\title{
Extracellular Matrix Enzymes and Immune Cell Biology
}

\author{
Meagan McMahon, Siying Ye, Jess Pedrina, Daniel Dlugolenski and John Stambas * \\ Faculty of Health, School of Medicine, Deakin University, Geelong, VIC, Australia
}

Remodelling of the extracellular matrix (ECM) by ECM metalloproteinases is increasingly being associated with regulation of immune cell function. ECM metalloproteinases, including Matrix Metalloproteinases (MMPs), A Disintegrin and Metalloproteinases (ADAMs) and ADAMs with Thombospondin-1 motifs (ADAMTS) play a vital role in pathogen defence and have been shown to influence migration of immune cells. This review provides a current summary of the role of ECM enzymes in immune cell migration and function and discusses opportunities and limitations for development of diagnostic and therapeutic strategies targeting metalloproteinase expression and activity in the context of infectious disease.

Keywords: immunity, extracellular matrix, metalloproteinases, a disintegrin and metalloproteinases with thombospondin-1 motifs, a disintegrin and metalloproteinases

\section{OPEN ACCESS}

Edited by:

Kazuhiro Yamamoto,

University of Liverpool,

United Kingdom

Reviewed by:

Andrea Venerando,

University of Padua, Italy

Murshidul Ahsan,

Yeungnam University, South Korea

*Correspondence:

John Stambas

john.stambas@deakin.edu.au

Specialty section:

This article was submitted to Protein Chemistry and Enzymology,

a section of the journal

Frontiers in Molecular Biosciences

Received: 30 April 2021

Accepted: 02 August 2021

Published: 30 August 2021

Citation:

McMahon M, Ye S, Pedrina J,

Dlugolenski D and Stambas J (2021)

Extracellular Matrix Enzymes and

Immune Cell Biology.

Front. Mol. Biosci. 8:703868.

doi: $10.3389 /$ fmolb.2021.703868

\section{INTRODUCTION}

The extracellular matrix (ECM) forms the structural architecture surrounding cells and plays a key role in supporting tissue integrity and cellular functions. Remodelling of the ECM by metalloproteinase enzymes has being increasingly linked to immunity, especially immune cell migration (Bradley et al., 2012; McMahon et al., 2016; Chen et al., 2018; Boyd et al., 2020). Immune cell migration is critical for resolution of infectious disease. Large populations of mature immune cells do not normally reside at the site of disease and are instead located in the circulation or secondary lymphoid organs where they can be called upon when required. For example, following influenza virus infection, $\mathrm{T}$ cells become activated, proliferate in the mediastinal lymph node and then migrate to the lung to assist with clearance of virus. Using a murine model of influenza virus infection, one study has proposed that A Disintegrin-like and metalloproteinase with Thrombospondin1 Motifs - 5 (ADAMTS-5), an ECM metalloproteinase, facilitates migration of influenza virus-specific $\mathrm{CD} 8^{+} \mathrm{T}$ cells from the mediastinal lymph node (MLN) to the lung following infection (McMahon, Ye et al., 2016). In the absence of ADAMTS-5, viral clearance was disrupted. Conversely, a study using an alternative murine influenza virus infection model demonstrated that a closely related ECM enzyme, ADAMTS-4, when expressed in fibroblasts, contributed to increased lung damage following infection (Boyd, Allen et al., 2020). These studies emphasise the importance of the ECM and ECM remodelling in disease outcomes following virus infection and highlight the potential for development of ECM-based therapeutics. Recent advances in the fields of the ECM biology, metalloproteinase biology and immune cell migration, and the potential application of this new knowledge to the treatment of infectious disease will be discussed in detail throughout this review.

\section{THE EXTRACELLULAR MATRIX COMPONENTS}

There are four major ECM components that contribute to structural integrity. These include proteoglycans, non-proteoglycan polysaccharides, fibres and multi-adhesive proteins. Each of these components has been shown to affect immune cell migration and will be discussed below. 


\section{Proteoglycans}

Proteoglycans are generated by most eukaryotic cells and consist of repeating units of covalently bound glycosaminoglycans (GAGs). GAGs provide adhesion points for a range of ECM molecules, including chemokines (Rot 1992; Wight 2002; Rot 2010). Chemokines have chemoattractant properties that drive leukocyte extravasation and migration through the ECM. The interaction between chemokines and GAGs is critical for immune cell recruitment and migration (Spillmann et al., 1998; Kuschert et al., 1999; Hirose, Kawashima et al., 2001; Li et al., 2002; Proudfoot et al., 2003). Versican, an ECM proteoglycan, binds C-C chemokine ligand (CCL) $-2,-5,-8$ and -21 (Hirose, Kawashima et al., 2001), all of which act as chemoattractants for immune cell migration (Murooka et al., 2008; Murphy 2010; Fang et al., 2012). GAGs also provide adhesion points for immune cells along migratory pathways (Gotte, 2003; Parish, 2006). Lumican, an ECM proteoglycan encoding a GAG domain, binds neutrophils helping them traverse the endothelial cell layer. It also promotes neutrophil migration via its interactions with $\beta 2$-integrins (Lee et al., 2009).

ECM proteoglycans can also inhibit migration of immune cells. Versican has been shown to bind hyaluronan, a nonsulphated GAG widely distributed in connective tissue that acts to maintain ECM integrity (Suwan et al., 2009). Activation of $\mathrm{T}$ cells with poly $\mathrm{I}: \mathrm{C}$ increased the viscosity of the ECM by facilitating versican-hyaluronan interactions, leading to the inhibition of $\mathrm{CD}^{+}{ }^{+} \mathrm{T}$ cell migration (Evanko et al., 2012). In support of this proposition, analysis of versican expression in human cervical cancer samples has suggested that increased versican expression in stromal cells inhibited $\mathrm{CD}^{+} \mathrm{T}$ cell invasion, preventing $\mathrm{CD}^{+} \mathrm{T}$ cell clearance of tumorigenic cells (Gorter et al., 2010). Furthermore, a build-up of versican in the mediastinal lymph nodes of Adamts $5^{-1-}$ mice was associated with accumulation and poor migration of virusspecific $\mathrm{CD}^{+} \mathrm{T}$ cells to the periphery following influenzavirus infection (McMahon et al., 2016). In contrast, versican expression in a poly (I:C)-induced acute lung injury mouse model has been shown to encourage leucocyte infiltration and accumulation into lungs (Chang et al., 2014; Kang et al., 2016). These studies highlight the need for additional research to understand the contribution of ECM proteoglycans to immune cell migration.

\section{Non-Proteoglycan Polysaccharides}

Hyaluronan is an ECM polysaccharide that consists of repeating units of glucuronic acid and $\mathrm{N}$-acetyl glucosamine that can adhere to cell surface molecules such as CD44 (Lesley et al., 1994; Karvinen et al., 2003; Ruffell and Johnson, 2008; Suwan et al., 2009, Stephen P.; Evanko et al., 2012). The interaction between CD44 and hyaluronan facilitates mononuclear leukocyte adhesion to mucosal smooth muscle colon cells in vitro following inflammatory (poly I:C) stimulus (de la Motte et al., 2003). Hyaluronan also interacts with CD44 on the surface of T cells and is important for migration and activation of these cells (Lesley et al., 1994). However, the link between hyaluronan, cell surface molecules and immune cell migration needs to be further explored.

\section{Fibres}

Collagen and elastin are the main structural fibres of the ECM, contributing to ECM stiffness and supporting tissue structure. Expression of collagen has been shown to alter migratory patterns of macrophages and T cells (Applegate et al., 1990; Li et al., 2003; Klose et al., 2013; Murray et al., 2013). Elastin can be degraded by metalloproteinase expressing macrophages and is critical for migration (Varga et al., 1997; Brassart et al., 1998; Hance et al., 2002; Antonicelli et al., 2007). Moreover, elastin degradation peptides encourage recruitment of mononuclear phagocytes (Varga et al., 1997; Brassart et al., 1998; Hance et al., 2002; Antonicelli et al., 2007). These studies highlight a key role for ECM fibres in immune cell migration. However, targeting ECM fibres for therapeutic use may prove difficult given the importance of these fibres in tissue structure.

\section{Multi-Adhesive Proteins}

The ECM also contains ligands, such as fibronectin and laminin, that provide structural attachment sites for migrating immune cells. Laminin is a fibrous protein present within the basal lamina of epithelial tissue. It forms an intricate protein network for cellular contact to enhance structural integrity of tissues. Laminin a4 (a sub-type of laminin) knockout mice $\left(\operatorname{Lam} \alpha 4^{-1-}\right)$ have been successfully used to determine the contribution of this ECM component to immune cell migration. Croton-oil administration to the skin of $L a m \alpha 4^{-1-}$ mice showed reduced neutrophil and monocyte infiltration towards the inflammatory stimulus (Wondimu et al., 2004; Kenne et al., 2010). Moreover, in the absence of Laminin $\alpha 4$, reduced $\mathrm{T}$ cell infiltration into the brain was observed in an experimental autoimmune encephalomyelitis mouse model (Wu et al., 2009).

\section{FUNCTION, STRUCTURE AND REGULATION OF ZINC-DEPENDENT METALLOPROTEINASES}

\section{Function}

In mammals, the zinc-dependent metalloproteinase (metzincin) superfamily includes 24 Matrix Metalloproteinases (MMPs) (Klein and Bischoff 2011), 40 A Disintegrin and Metalloproteinases (ADAMs) and 19 ADAMTS metalloproteinases (Brocker et al., 2009; Duffy et al., 2009; Mead and Apte, 2018). Of these, only 23 MMPs and 21 ADAMs have been identified in humans, while all 19 ADAMTS family members are found in humans (RaeeszadehSarmazdeh et al., 2020). Metalloproteinases (MMPs, ADAMs and ADAMTSs) collectively cleave a large array of ECM substrates including proteoglycans, collagens and membrane-associated protein substrates such as cytokines (Black et al., 1997; Khatwa et al., 2010). Functionally, MMPs are responsible for regulating and degrading a variety of ECM components including collagen, elastin, and gelatin and contribute to regulation of cytokine expression ( $\mathrm{Ra}$ and Parks, 2007; Siddhartha and Garg, 2021). Similarly, ADAMs cleave and release soluble factors like chemokines (Reiss and Saftig, 2009), mediate shedding of membrane-associated proteins into their active 


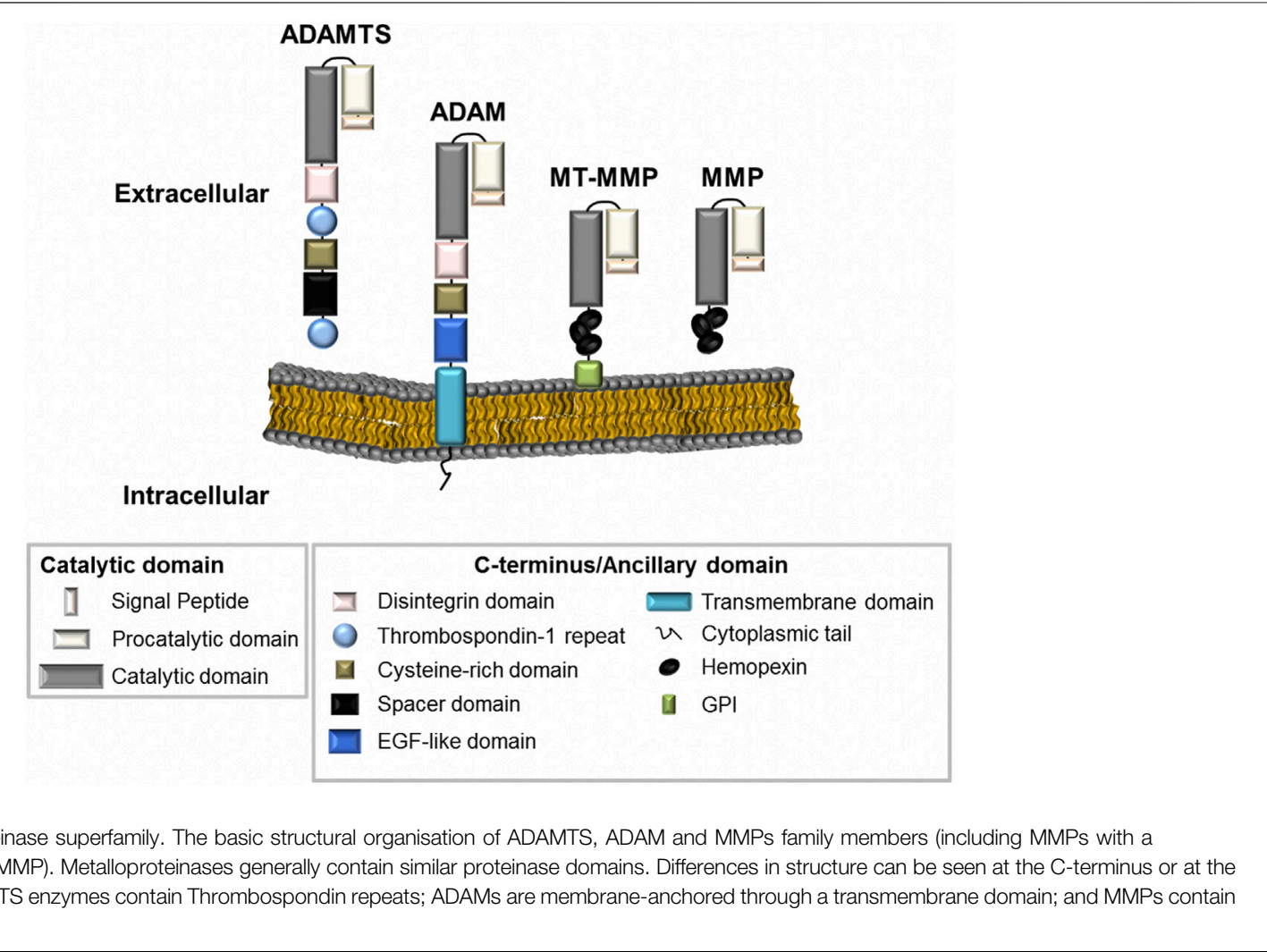

forms (i.e. TNF- $\alpha$ ) (Black et al., 1997) or regulate gene expression through the generation of molecules that potentially act as transcription factors following intramembrane proteolysis and translocation to the nucleus (Reiss and Saftig, 2009). ADAMTSs are categorized based on cleavage substrates within the ECM-substrates include proteoglycans, pro-collagen N-propeptides, cartilage oligomeric matrix protein (COMP), and unknown or "orphan substrates" (Kelwick et al., 2015). A group of ADAMTS enzymes (ADAMTS-1, -4, -5, -8, -9, -15 and -20$)$ can cleave aggrecan, versican, brevican, and neurocan and are termed "hyalectinases" (Abbaszade, Liu et al., 1999; Boerboom et al., 2011; Dancevic et al., 2013; Dancevic and McCulloch 2014). Cleavage of these ECM substrates allow metalloproteinases to play a key functional role in migration, proliferation and differentiation of cells. The role of metalloproteinases in the migration of immune cells will be discussed in detail below.

\section{Structure}

All metzincins are synthesized as zymogens that contain a prodomain and a catalytic domain for enzymatic activity, along with a distinctive C-terminus or ancillary domain (Massova et al., 1998; Nagase et al., 2006) (Figure 1). MMPs can be distinguished by the presence of a haemopexin-like domain that facilitates adhesion to their various substrates. MMPs are divided into three main categories-collagenases, gelatinases, and stromelysins based on their substrate specificity. They can also be categorized by the presence or absence of a transmembrane domain, allowing them to exist either as membrane-anchored or secreted metalloproteinases (Figure 1) (Klein and Bischoff, 2011). ADAMs and ADAMTS are distinguished from MMPs by the presence of a disintegrin or disintegrin-like domain, respectively. Metalloproteinase structure has been reviewed extensively and further information for these enzyme families can be found in the following review articles (Birkedal-Hansen, 1988; BirkedalHansen et al., 1993; Massova et al., 1998; Tang, 2001; Apte, 2009).

\section{Activation and Regulation}

Metalloproteinases contain a conserved methionine residue at the active site and use a zinc ion for catalysis in enzymatic reactions (Bode et al., 1993). Activation of metalloproteinases varies depending on which type of zinc protease they represent; MMP, ADAM or ADAMTS. MMPs are synthesized and secreted as inactive enzymes. They remain in a latent state until they undergo catalytic activation by pro-protein convertases, such as furin ( $\mathrm{Ra}$ and Parks, 2007). Catalytic activation of ADAMs occurs mostly intracellularly prior to secretion where they are found in their active form (Lum et al., 1998; Roghani et al., 1999; Kang et al., 2002). ADAMTSs share similarities with both ADAMs and MMPs and can be secreted in their inactive "pro" form or can be activated intracellularly and then secreted (Longpre et al., 2009; Kelwick et al., 2015). Metalloproteinase-mediated catalytic activity can be up-regulated or inhibited. Regulation and inhibition by host factors including reversion-inducing cysteine-rich protein with Kazal motifs, $a$-macroglobulin and 
the tissue inhibitors of metalloproteinases (TIMPs) has been characterized (Brew and Nagase, 2010). All four of the TIMP (TIMP-1-4) family members broadly inhibit MMPs (Greene et al., 1996; Ikonomidis et al., 2005; Jacobsen et al., 2008; Brew and Nagase, 2010; Kveiborg et al., 2010), with TIMP-3 inhibiting all MMPs, ADAM-10, $-12,-17,-28$ and -33 , as well as ADAMTS-1, $-2,-4$ and -5 (Amour et al., 2000; Kashiwagi et al., 2001; Wang et al., 2006). These regulators of metalloproteinase activity can therefore be used to study disease processes.

\section{METALLOPROTEINASE REGULATION OF IMMUNE CELL MIGRATION}

As discussed above, ECM molecules are capable of inhibiting and supporting migration of immune cells. Immune cells (or relevant surrounding cells) express distinct metalloproteinases that interact with components of the ECM such as collagen and proteoglycans, to inhibit or promote immune cell migration.

\section{Neutrophils}

Neutrophils secrete a range of pro-inflammatory molecules and immune mediators (reactive oxygen species, defensins and TNFa), which have potent antiviral and antibacterial activity against infected cells. However, excessive neutrophil infiltration following inflammatory stimulus can lead to tissue damage and exacerbation of disease. Neutrophil infiltration into the lungs of mice infected with a laboratory adapted influenza virus (A/Puerto Rico/8/1934 (H1N1)) correlates with increased expression of MMP-2 and MMP-9, leading to pathology associated with enhanced cellular infiltrates and destruction of lung architecture (Bradley et al., 2012). In support of this, influenza virus infection results in MMP-9 secretion by neutrophils to facilitate infiltration into alveoli of the lung, which can be associated with poor disease outcomes in these mice (Wang et al., 2010; Narasaraju et al., 2011; Bradley et al., 2012). However, Bradley et al (2012), also demonstrate that MMP-9 expression is necessary for normal, protective neutrophil infiltration associated with viral clearance (Bradley et al., 2012).

\section{Macrophages}

To enter tissue, macrophages must first traverse the basement membrane (Kelley et al., 2014; Tsuji et al., 2018). Macrophageinduced MMP-2, MMP-9, and MMP-14 (MT1-MMP) enzymatic activity facilitates infiltration and degradation of collagen in the basement membrane for a number of diseases, including fibrosis, vasculitis, and dermatitis. (Ray et al., 2004; Nishida et al., 2007; Gong et al., 2008; Klose et al., 2013; Watanabe et al., 2018). Indeed, depletion of plasminogen, which normally activates MMP-9 into its catalytically active form, results in reduced macrophage infiltration and a decreased likelihood of aortic aneurysm in a murine model of abdominal aortic aneurysm (Gong et al., 2008). In addition, reduced renal fibrosis was observed in $\mathrm{Mmp}-2^{-/-}$mice following unilateral ureteral obstruction (Du et al., 2012). MMP-14 has also been shown to be involved in macrophage infiltration in a murine model of contact dermatitis, where in $\mathrm{Mmp}-14^{-/-}$mice showed reduced macrophage infiltration at the site of dermatitis (Klose et al., 2013). These studies highlight the importance for MMPs in macrophage migration. In addition, related enzymes including ADAMs (ADAMs-8, -9, -15 and -19) and ADAMTS (ADAMTS-1, $-4,-5$ and -8) are found to be highly expressed in macrophage-rich areas in atherosclerosis. It is currently unclear if expression of these enzymes enhances macrophage infiltrating potential (Wågsäter et al., 2008; Salter et al., 2011).

\section{Dendritic Cells}

Efficient dendritic cell (DC) migration is critical for initiating adaptive immune cell responses. In the absence of DC signaling, adaptive immune cell activation is severely impaired. The role of metalloproteinases in DC migration is currently under-studied. In vitro migration assays indicate that DCs isolated from $M m p 9^{-/-}$mice show reduced migration when compared to their WT counterparts (Yen et al., 2008). To further expand on the role of $M M P-9$ in DC migration, DC trafficking during allergen-induced airway inflammation in $\mathrm{Mmp}^{-1-}$ mice was assessed (Vermaelen et al., 2003). In the absence of MMP-9, inflammatory migration of DCs into the airway lumen was restricted, preventing the development of allergic airway inflammation. These studies highlight the importance of further defining the role of metalloproteinase mediated migration of DCs in acute and chronic disease.

\section{T Cells}

Effector T cells do not normally reside at sites of disease. They are activated by DCs in lymph nodes and migrate to sites where they are required to perform their function. Indeed, migrating $\mathrm{T}$ cells in the high endothelial venules of lymph nodes require MMP-2 and -9 for normal migration (Faveeuw et al., 2001). Peripheral blood mononuclear cells derived from multiple sclerosis patients have been used to determine differences in migration of $\mathrm{CD}^{+}$ $\mathrm{T}$ cell subpopulations in vitro using a transwell migration assay. $\mathrm{T}$ helper 1 (Th1) $\mathrm{CD}^{+} \mathrm{T}$ cells isolated from the aforementioned multiple sclerosis patients secreted higher amounts of MMP-2 and -9 when compared to Th2 $\mathrm{CD}^{+}{ }^{+} \mathrm{T}$ cells, which was reflected through increased mobility in the transwell system (Abraham et al., 2005). Furthermore, inhibition of the Wnt pathway (a regulator of $\mathrm{MMP}-2$ and -9 expression) results in reduced MMP-2 and -9 expression, leading to collagen accumulation and inhibition of $\mathrm{T}$ cell extravasation (Wu et al., 2007). The absence of MMP-2 and -9 in mice disrupts cleavage of collagen type IV and T cell movement through the ECM (Wu et al., 2007). Other ECM enzymes have also been shown to affect $\mathrm{T}$ cell migration. In human myeloma biopsy samples, one study has shown that samples containing high numbers of $\mathrm{CD} 8^{+} \mathrm{T}$ cells also demostrated elevated versican proteolysis via ADAMTS enzymes, suggesting these enzymes are important for T cell clearance of tumours (Hope et al., 2016). Mice lacking ADAMTS-5 (Adamts $5^{-/-}$mice) show reduced movement of virus-specific $\mathrm{CD}^{+} \mathrm{T}$ cells following influenza virus infection (McMahon et al., 2016). Mechanistic analyses suggested that versican 
accumulation in the draining mediastinal lymph node interrupted egress of $\mathrm{CD}^{+} \mathrm{T}$ cells from the mediastinal lymph node to the periphery (McMahon et al., 2016). This result was further supported in vitro, where Jurkat $\mathrm{CD}^{+} \mathrm{T}$ human cells treated with an anti-ADAMTS5 antibody also showed impaired migration through versican in a transwell migration assay (McMahon et al., 2016). While the absence of ADAMTS-5 resulted in poor virus clearance and increased disease severity that was attributed to T cell migration (McMahon et al., 2016), a recent study by (Boyd et al., 2020) has demonstrated that the absence of a closely related family member, ADAMTS-4 in fibroblasts, leads to reduced lung immunopathology and improved lung function following lethal influenza virus infection (Boyd et al., 2020). This highlights the potential of these enzymes to influence outcomes of infection and emphasizes the need for further studies.

\section{Metalloproteinase-Mediated Cleavage of Cytokines to Promote Immune Cell Migration}

Chemokines are a group of signaling molecules that are secreted by cells to promote migration of immune cells to the site of inflammation or disease. Neutrophils are typically the first cell type to respond to infection and infiltration may be supported by metalloproteinase activity. Nasal biopsies taken from allergic rhinitis patients, show that upregulated ADAM-12 in airway epithelial cells results in cleavage and release of the neutrophil chemoattractants, CXCL-1 and -8, from the ECM, which assist in the recruitment of neutrophils into the nasal cavity (Estrella et al., 2009). The use of Mmp knockout mouse models has also identified roles for MMP-7 and -8 in creating neutrophil chemotactic gradients. In $\mathrm{Mmp}^{-1-}$ mice, lung injury induced by bleomycin treatment resulted in a reduced transepithelial gradient of the chemokine KC (CXCL1), leading to reduced neutrophil influx (Li et al., 2002). Additionally, using a mouse model of acute colon injury Swee et al showed that the reduced neutrophil influx observed in $\mathrm{Mmp}^{-1-}$ mice due to changes in chemotactic gradients protected them from succumbing to colon injury, but that repair of colon tissue was delayed in these mice (Swee et al., 2008). These studies highlight the importance of metalloproteinase-mediated cleavage of cytokines in disease and exemplify an important role for this cleavage in promoting and controlling immune cell migration.

\section{Emerging and Future Areas of Interest}

Metalloproteinases are attractive therapeutic targets where modulation of immune responses is required. They are essential for immune cell infiltration, cytokine regulation and tissue repair (Davey et al., 2011) and have the potential to be used as targets through the use of currently approved therapeutics or can be targeted by compounds under development; both of which have been eloquently reviewed by Raeeszadeh-Sarmazdeh et al., 2020 and Santamaria and de Groot, 2019 (Santamaria and de Groot, 2019; Raeeszadeh-Sarmazdeh et al., 2020). Of these potential therapeutics, the most widely studied include, small molecule inhibitors, antibody-based inhibitors, and tissue inhibitors of metalloproteinases (TIMPs), which are the natural regulators of metalloproteinase activity.

Small molecule inhibitors can elicit their inhibitory effects by targeting specific sites of the enzyme itself (catalytic or otherwise) and have been shown to target MMPs, ADAMs and ADAMTSs (Dufour et al., 2011; Remacle et al., 2012; Raeeszadeh-Sarmazdeh et al., 2020; Santamaria, 2020; Santamaria et al., 2021). While many of these compounds have shown potential in preclinical and clinical settings, off-target effects, lack of selectivity and specificity, and toxicity are all issues that need to be addressed (Cathcart et al., 2015; Mushtaq et al., 2018). In comparison to small molecule inhibitors, antibody-based inhibition is typically associated with less toxicity and immunogenicity (Fischer and Riedl 2019; Raeeszadeh-Sarmazdeh et al., 2020). As with small molecule inhibitors, antibodies have demonstrated varying degrees of success in targeting metalloproteinases in preclinical and clinical trials. Studies currently underway are assessing their use in the context of human health. (Dancevic and McCulloch, 2014; Santamaria et al., 2015; Shiraishi et al., 2016; Balchen et al., 2018; Santamaria and de Groot 2019; Raeeszadeh-Sarmazdeh et al., 2020). Manipulation of TIMPs may offer an alternative therapeutic approach. Given these proteins are natural regulators of MMPs, ADAMs and ADAMTSs, manipulation of TIMPs is a logical extension of inquiry. However, previous studies have highlighted both positive and negative outcomes to disease progression as reviewed by Raeeszadeh-Sarmazdeh et al., 2020 (Raeeszadeh-Sarmazdeh et al., 2020). This highlights the need for detailed understanding of TIMP regulation of metalloproteinase activity to inform development of future therapeutic options.

Conversely, as described throughout this review, enhanced expression of metalloproteinases may prove beneficial in certain disease states when increased immune cell migration is desired. While there are no therapeutics currently available that facilitate overexpression of these enzymes in clinical trial, to the best of our knowledge, the vast array of emerging inhibitors suggests that the same effect may be achieved via inhibition of the negative regulators themselves ie TIMPs. It is important to note however, that over-active metalloproteinase activity in other disease contexts e.g arthritis, has been shown to cause inflammation, leading to tissue destruction and poor outcomes in the host as observed in both human and animal studies (Davey et al., 2011; Syed et al., 2021).

Finally, although manipulating individual metalloproteinases seems reasonable, we are yet to fully elucidate how metalloproteinases act synergistically, and need to consider compensatory metalloproteinase activity in such instances. Moreover, many studies examining the function of multiple metalloproteinases in immunity have only been employed in vitro models, which do not take into account multi-faceted defence mechanisms elicited by a whole organism towards disease. Similarly most, in vivo metalloproteinase knock-out animal models have only dissected the role of individual metalloproteinases in disease processes although use of Adamts ${ }^{-1-} x$ Adamts $12^{-1-}$ mice and Adamts $4^{-1-} x$ Adamts $5^{-1-}$ mice have been reported (Majumdar et al., 2007; Mead et al., 2018). Further in vivo studies are required to understand how metalloproteinases act individually and synergistically before 
therapeutic intervention becomes a realistic treatment in the clinic.

\section{CONCLUSION}

Metalloproteinases play an important role in regulating remodeling of the ECM to facilitate immune cell activity. Understanding how metalloproteinase activity is regulated and how family members act synergistically to influence immunity is critically important in order to develop novel therapeutic strategies.

\section{REFERENCES}

Abbaszade, I., Liu, R.-Q., Yang, F., Rosenfeld, S. A., Ross, O. H., Link, J. R., et al. (1999). Cloning and Characterization of ADAMTS11, an Aggrecanase from the ADAMTS Family. J. Biol. Chem. 274 (33), 23443-23450. doi:10.1074/ jbc. 274.33 .23443

Abraham, M., Shapiro, S., Karni, A., Weiner, H. L., and Miller, A. (2005). Gelatinases (MMP-2 and MMP-9) Are Preferentially Expressed by Th1 vs. Th2 Cells. J. Neuroimmunol 163 (1-2), 157-164. doi:10.1016/ j.jneuroim.2005.02.001

Amour, A., Knight, C. G., Webster, A., Slocombe, P. M., Stephens, P. E., Knäuper, V., et al. (2000). The In Vitro Activity of ADAM-10 Is Inhibited by TIMP-1 and TIMP-3. FEBS Lett. 473 (3), 275-279. doi:10.1016/s0014-5793(00)01528-3

Antonicelli, F., Bellon, G., Debelle, L., and Hornebeck, W. (2007). Elastin-Elastases and Inflamm-Aging. Curr. Top. Dev. Biol. 79, 99-155. doi:10.1016/s00702153(06)79005-6

Applegate, K. G., Balch, C. M., and Pellis, N. R. (1990). In Vitro migration of Lymphocytes through Collagen Matrix: Arrested Locomotion in TumorInfiltrating Lymphocytes. Cancer Res. 50 (22), 7153-7158.

Apte, S. S. (2009). A Disintegrin-like and Metalloprotease (Reprolysin-type) with Thrombospondin Type 1 Motif (ADAMTS) Superfamily: Functions and Mechanisms. J. Biol. Chem. 284 (46), 31493-31497. doi:10.1074/ jbc.r109.052340

Balchen, T., Strotmann, R., Reinstrup Bihlet, A., Sonne, J., Ladel, C., Moreau, F., et al. (2018). Study Design of a Phase I, Placebo-Controlled, First-In-Human Trial to Assess Safety and Tolerability, Immunogenicity, and Pharmacokinetics and Pharmacodynamics of Single Ascending Doses of the Anti-ADAMTS-5 Nanobody, M6495, in Healthy Male Subjects. Osteoarthritis and Cartilage 26, S276-S277. doi:10.1016/j.joca.2018.02.561

Birkedal-Hansen, H. (1988). From Tadpole Collagenase to a Family of Matrix Metalloproteinases. J. Oral Pathol. 17 (9-10), 445-451. doi:10.1111/j.16000714.1988.tb01313.x

Birkedal-Hansen, H., Moore, W. G. I., Bodden, M. K., Windsor, L. J., BirkedalHansen, B., DeCarlo, A., et al. (1993). Matrix Metalloproteinases: a Review. Crit. Rev. Oral Biol. Med. 4 (2), 197-250. doi:10.1177/ 10454411930040020401

Black, R. A., Rauch, C. T., Kozlosky, C. J., Peschon, J. J., Slack, J. L., Wolfson, M. F., et al. (1997). A Metalloproteinase Disintegrin that Releases Tumour-Necrosis Factor- $\alpha$ from Cells. Nature 385 (6618), 729-733. doi:10.1038/385729a0

Bode, W., Stöckler, F. X. W., and Stockler, W. (1993). Astacins, Serralysins, Snake Venom and Matrix Metalloproteinases Exhibit Identical Zinc-Binding Environments (HEXXHXXGXXH and Met-Turn) and Topologies and Should Be Grouped into a Common Family, the 'metzincins'. FEBS Lett. 331 (1-2), 134-140. doi:10.1016/0014-5793(93)80312-i

Boerboom, D., Lafond, J.-F., Zheng, X., Lapointe, E., Mittaz, L., Boyer, A., et al. (2011). Partially Redundant Functions of Adamts1 and Adamts4 in the Perinatal Development of the Renal Medulla. Dev. Dyn. 240 (7), 1806-1814. doi:10.1002/dvdy.22662

Boyd, D. F., Allen, E. K., Randolph, A. G., Guo, X. J., Weng, Y., Sanders, C. J., et al. (2020). Exuberant Fibroblast Activity Compromises Lung Function via ADAMTS4. Nature 587, 466. doi:10.1038/s41586-020-2877-5

Bradley, L. M., Douglass, M. F., Chatterjee, D., Akira, S., and Baaten, B. J. G. (2012). Matrix Metalloprotease 9 Mediates Neutrophil Migration into the Airways in

\section{AUTHOR CONTRIBUTIONS}

All authors listed have made a substantial, direct, and intellectual contribution to the work and approved it for publication.

\section{FUNDING}

NHMRC APP1158951; funding to support a post-doctoral fellow and laboratory expenses.

Response to Influenza Virus-Induced Toll-like Receptor Signaling. Plos Pathog 8 (4), e1002641. doi:10.1371/journal.ppat.1002641

Brassart, B., Randoux, A., Hornebeck, W., and Emonard, H. (1998). Regulation of Matrix Metalloproteinase-2(gelatinase A, MMP-2), Membrane-type Matrixmetalloproteinase-1 (MT1-MMP) and Tissue Inhibitorof Metalloproteinases-2 (TIMP-2) Expression Byelastin-Derived Peptides in Human HT-1080 Fibrosarcoma Cell Line. Clin. Exp. Metastasis 16 (6), 489-500. doi:10.1023/a:1006550503612

Brew, K., and Nagase, H. (2010). The Tissue Inhibitors of Metalloproteinases (TIMPs): An Ancient Family with Structural and Functional Diversity. Biochim. Biophys. Acta (Bba) - Mol. Cel Res. 1803 (1), 55-71. doi:10.1016/ j.bbamcr.2010.01.003

Brocker, C. N., Vasiliou, V., and Nebert, D. W. (2009). Evolutionary Divergence and Functions of the ADAM and ADAMTS Gene Families. Hum. Genomics 4 (1), 43-55. doi:10.1186/1479-7364-4-1-43

Cathcart, J., Pulkoski-Gross, A., and Cao, J. (2015). Targeting Matrix Metalloproteinases in Cancer: Bringing New Life to Old Ideas. Genes Dis. 2 (`1), 26-34. doi:10.1016/j.gendis.2014.12.002

Chang, M. Y., Tanino, Y., Vidova, V., Kinsella, M. G., Chan, C. K., Johnson, P. Y., et al. (2014). A Rapid Increase in Macrophage-Derived Versican and Hyaluronan in Infectious Lung Disease. Matrix Biol. 34, 1-12. doi:10.1016/ j.matbio.2014.01.011

Chen, J., Luo, Y., Zhou, Y., Qin, S., Qiu, Y., Cui, R., et al. (2018). Promotion of Tumor Growth by ADAMTS4 in Colorectal Cancer: Focused on Macrophages. Cell Physiol Biochem 46 (4), 1693-1703. doi:10.1159/000489245

Dancevic, C. M., Fraser, F. W., Smith, A. D., Stupka, N., Ward, A. C., and McCulloch, D. R. (2013). Biosynthesis and Expression of a Disintegrin-like and Metalloproteinase Domain with Thrombospondin-1 Repeats-15. J. Biol. Chem. 288 (52), 37267-37276. doi:10.1074/jbc.m112.418624

Dancevic, C. M., and McCulloch, D. R. (2014). Current and Emerging Therapeutic Strategies for Preventing Inflammation and Aggrecanase-Mediated Cartilage Destruction in Arthritis. Arthritis Res. Ther. 16 (5), 429. doi:10.1186/s13075014-0429-9

Davey, A., McAuley, D. F., and O'Kane, C. M. (2011). Matrix Metalloproteinases in Acute Lung Injury: Mediators of Injury and Drivers of Repair. Eur. Respir. J. 38 (4), 959-970. doi:10.1183/09031936.00032111

de la Motte, C. A., Hascall, V. C., Drazba, J., Bandyopadhyay, S. K., and Strong, S. A. (2003). Mononuclear Leukocytes Bind to Specific Hyaluronan Structures on Colon Mucosal Smooth Muscle Cells Treated with Polyinosinic Acid: Polycytidylic Acid. Am. J. Pathol. 163 (1), 121-133. doi:10.1016/s00029440(10)63636-x

Du, X., Shimizu, A., Masuda, Y., Kuwahara, N., Arai, T., Kataoka, M., et al. (2012). Involvement of Matrix Metalloproteinase-2 in the Development of Renal Interstitial Fibrosis in Mouse Obstructive Nephropathy. Lab. Invest. 92 (8), 1149-1160. doi:10.1038/labinvest.2012.68

Duffy, M. J., McKiernan, E., O’Donovan, N., and McGowan, P. M. (2009). The Role of ADAMs in Disease Pathophysiology. Clin. Chim. Acta 403 (1-2), 31-36. doi:10.1016/j.cca.2009.01.007

Dufour, A., Sampson, N. S., Li, J., Kuscu, C., Rizzo, R. C., Deleon, J. L., et al. (2011). Small-molecule Anticancer Compounds Selectively Target the Hemopexin Domain of Matrix Metalloproteinase-9. Cancer Res. 71 (14), 4977-4988. doi:10.1158/0008-5472.can-10-4552

Estrella, C., Rocks, N., Paulissen, G., Quesada-Calvo, F., Noël, A., Vilain, E., et al. (2009). Role of A Disintegrin and Metalloprotease-12 in Neutrophil 
Recruitment Induced by Airway Epithelium. Am. J. Respir. Cel Mol Biol 41 (4), 449-458. doi:10.1165/rcmb.2008-0124oc

Evanko, S. P., Potter-Perigo, S., Bollyky, P. L., Nepom, G. T., and Wight, T. N. (2012). Hyaluronan and Versican in the Control of Human T-Lymphocyte Adhesion and Migration. Matrix Biol. 31 (2), 90-100. doi:10.1016/ j.matbio.2011.10.004

Fang, W. B., Jokar, I., Zou, A., Lambert, D., Dendukuri, P., and Cheng, N. (2012). CCL2/CCR2 Chemokine Signaling Coordinates Survival and Motility of Breast Cancer Cells through Smad3 Protein- and P42/44 Mitogen-Activated Protein Kinase (MAPK)-dependent Mechanisms. J. Biol. Chem. 287 (43), 36593-36608. doi:10.1074/jbc.m112.365999

Faveeuw, C., Preece, G., and Ager, A. (2001). Transendothelial Migration of Lymphocytes across High Endothelial Venules into Lymph Nodes Is Affected by Metalloproteinases. Blood 98 (3), 688-695. doi:10.1182/ blood.v98.3.688

Fischer, T., and Riedl, R. (2019). Inhibitory Antibodies Designed for Matrix Metalloproteinase Modulation. Molecules 24 (12), 2265. doi:10.3390/ molecules 24122265

Gong, Y., Hart, E., Shchurin, A., and Hoover-Plow, J. (2008). Inflammatory Macrophage Migration Requires MMP-9 Activation by Plasminogen in Mice. J. Clin. Invest. 118 (9), 3012-3024. doi:10.1172/jci32750

Gorter, A., Zijlmans, H. J., van Gent, H., Trimbos, J. B., Fleuren, G. J., and Jordanova, E. S. (2010). Versican Expression Is Associated with TumorInfiltrating CD8-Positive $\mathrm{T}$ Cells and Infiltration Depth in Cervical Cancer. Mod. Pathol. 23 (12), 1605-1615. doi:10.1038/ modpathol.2010.154

Götte, M. (2003). Syndecans in Inflammation. FASEB j. 17 (6), 575-591. doi:10.1096/fj.02-0739rev

Greene, J., Wang, M., Liu, Y. E., Raymond, L. A., Rosen, C., and Shi, Y. E. (1996). Molecular Cloning and Characterization of Human Tissue Inhibitor of Metalloproteinase 4. J. Biol. Chem. 271 (48), 30375-30380. doi:10.1074/ jbc.271.48.30375

Hance, K. A., Tataria, M., Ziporin, S. J., Lee, J. K., and Thompson, R. W. (2002). Monocyte Chemotactic Activity in Human Abdominal Aortic Aneurysms: Role of Elastin Degradation Peptides and the 67-kD Cell Surface Elastin Receptor. J. Vasc. Surg. 35 (2), 254-261. doi:10.1067/mva.2002.120382

Hirose, J., Kawashima, H., Yoshie, O., Tashiro, K., and Miyasaka, M. (2001). Versican Interacts with Chemokines and Modulates Cellular Responses. J. Biol. Chem. 276 (7), 5228-5234. doi:10.1074/jbc.m007542200

Hope, C., Foulcer, S., Jagodinsky, J., Chen, S. X., Jensen, J. L., Patel, S., et al. (2016). Immunoregulatory Roles of Versican Proteolysis in the Myeloma Microenvironment. Blood 128 (5), 680-685. doi:10.1182/blood-2016-03705780

Ikonomidis, J. S., Hendrick, J. W., Parkhurst, A. M., Herron, A. R., Escobar, P. G., Dowdy, K. B., et al. (2005). Accelerated LV Remodeling after Myocardial Infarction in TIMP-1-Deficient Mice: Effects of Exogenous MMP Inhibition. Am. J. Physiology-Heart Circulatory Physiol. 288 (1), H149-H158. doi:10.1152/ ajpheart.00370.2004

Jacobsen, J., Visse, R., Sørensen, H. P., Enghild, J. J., Brew, K., Wewer, U. M., et al. (2008). Catalytic Properties of ADAM12 and its Domain Deletion Mutants. Biochemistry 47 (2), 537-547. doi:10.1021/bi701629c

Kang, I., Harten, I. A., Chang, M. Y., Braun, K. R., Sheih, A., Nivison, M. P., et al. (2016). Versican Deficiency Significantly Reduces Lung Inflammatory Response Induced by Polyinosine-Polycytidylic Acid Stimulation. J. Biol. Chem. 292, 51. doi:10.1074/jbc.M116.753186

Kang, T., Zhao, Y.-G., Pei, D., Sucic, J. F., and Sang, Q.-X. A. (2002). Intracellular Activation of Human Adamalysin 19/Disintegrin and Metalloproteinase 19 by Furin Occurs via One of the Two Consecutive Recognition Sites. J. Biol. Chem. 277 (28), 25583-25591. doi:10.1074/jbc.m203532200

Karvinen, S., Kosma, V.-M., Tammi, M. I., and Tammi, R. (2003). Hyaluronan, CD44 and Versican in Epidermal Keratinocyte Tumours. Br. J. Dermatol. 148 (1), 86-94. doi:10.1046/j.1365-2133.2003.05028.x

Kashiwagi, M., Tortorella, M., Nagase, H., and Brew, K. (2001). TIMP-3 Is a Potent Inhibitor of Aggrecanase 1 (ADAM-TS4) and Aggrecanase 2 (ADAMTS5). J. Biol. Chem. 276 (16), 12501-12504. doi:10.1074/jbc.c000848200

Kelley, L. C., Lohmer, L. L., Hagedorn, E. J., and Sherwood, D. R. (2014). Traversing the Basement Membrane In Vivo: a Diversity of Strategies. J. Cel Biol 204 (3), 291-302. doi:10.1083/jcb.201311112
Kelwick, R., Desanlis, I., Wheeler, G. N., and Edwards, D. R. (2015). The ADAMTS (A Disintegrin and Metalloproteinase with Thrombospondin Motifs) Family. Genome Biol. 16, 113. doi:10.1186/s13059-015-0676-3

Kenne, E., Soehnlein, O., Genové, G., Rotzius, P., Eriksson, E. E., and Lindbom, L. (2010). Immune Cell Recruitment to Inflammatory Loci Is Impaired in Mice Deficient in Basement Membrane Protein Laminin a4. J. Leukoc. Biol. 88 (3), 523-528. doi:10.1189/jlb.0110043

Khatwa, U. A., Kleibrink, B. E., Shapiro, S. D., and Subramaniam, M. (2010). MMP8 Promotes Polymorphonuclear Cell Migration through Collagen Barriers in Obliterative Bronchiolitis. J. Leukoc. Biol. 87 (1), 69-77. doi:10.1189/ jlb.0509361

Klein, T., and Bischoff, R. (2011). Physiology and Pathophysiology of Matrix Metalloproteases. Amino Acids 41 (2), 271-290. doi:10.1007/s00726-0100689-x

Klose, A., Zigrino, P., and Mauch, C. (2013). Monocyte/macrophage MMP-14 Modulates Cell Infiltration and T-Cell Attraction in Contact Dermatitis but Not in Murine Wound Healing. Am. J. Pathol. 182 (3), 755-764. doi:10.1016/ j.ajpath.2012.11.028

Kuschert, G. S. V., Coulin, F., Power, C. A., Proudfoot, A. E. I., Hubbard, R. E., Hoogewerf, A. J., et al. (1999). Glycosaminoglycans Interact Selectively with Chemokines and Modulate Receptor Binding and Cellular Responses. Biochemistry 38 (39), 12959-12968. doi:10.1021/bi990711d

Kveiborg, M., Jacobsen, J., Lee, M.-H., Nagase, H., Wewer, U. M., and Murphy, G. (2010). Selective Inhibition of ADAM12 Catalytic Activity through Engineering of Tissue Inhibitor of Metalloproteinase 2 (TIMP-2). Biochem. J. 430 (1), 79-86. doi:10.1042/bj20100649

Lee, S., Bowrin, K., Hamad, A. R., and Chakravarti, S. (2009). Extracellular Matrix Lumican Deposited on the Surface of Neutrophils Promotes Migration by Binding to $\beta 2$ Integrin. J. Biol. Chem. 284 (35), 23662-23669. doi:10.1074/ jbc.m109.026229

Lesley, J., Howes, N., Perschl, A., and Hyman, R. (1994). Hyaluronan Binding Function of CD44 Is Transiently Activated on T Cells during an In Vivo Immune Response. J. Exp. Med. 180 (1), 383-387. doi:10.1084/ jem.180.1.383

Li, Q., Fukuda, K., Lu, Y., Nakamura, Y., Chikama, T.-i., Kumagai, N., et al. (2003). Enhancement by Neutrophils of Collagen Degradation by Corneal Fibroblasts. J. Leukoc. Biol. 74 (3), 412-419. doi:10.1189/jlb.0801757

Li, Q., Park, P. W., Wilson, C. L., and Parks, W. C. (2002). Matrilysin Shedding of Syndecan-1 Regulates Chemokine Mobilization and Transepithelial Efflux of Neutrophils in Acute Lung Injury. Cell 111 (5), 635-646. doi:10.1016/s00928674(02)01079-6

Longpré, J.-M., McCulloch, D. R., Koo, B.-H., Alexander, J. P., Apte, S. S., and Leduc, R. (2009). Characterization of proADAMTS5 Processing by Proprotein Convertases. Int. J. Biochem. Cel Biol. 41 (5), 1116-1126. doi:10.1016/ j.biocel.2008.10.008

Lum, L., Reid, M. S., and Blobel, C. P. (1998). Intracellular Maturation of the Mouse Metalloprotease Disintegrin MDC15. J. Biol. Chem. 273 (40), 26236-26247. doi:10.1074/jbc.273.40.26236

Majumdar, M. K., Askew, R., Schelling, S., Stedman, N., Blanchet, T., Hopkins, B., et al. (2007). Double-knockout of ADAMTS- 4 and ADAMTS-5 in Mice Results in Physiologically normal Animals and Prevents the Progression of Osteoarthritis. Arthritis Rheum. 56 (11), 3670-3674. doi:10.1002/art.23027

Massova, I., Kotra, L. P., Fridman, R., and Mobashery, S. (1998). Matrix Metalloproteinases: Structures, Evolution, and Diversification. FASEB j. 12 (12), 1075-1095. doi:10.1096/fasebj.12.12.1075

McMahon, M., Ye, S., Izzard, L., Dlugolenski, D., Tripp, R. A., Bean, A. G. D., et al. (2016). ADAMTS5 Is a Critical Regulator of Virus-specific T Cell Immunity. Plos Biol. 14 (11), e1002580. doi:10.1371/journal.pbio.1002580

Mead, T. J., McCulloch, D. R., Ho, J. C., Du, Y., Adams, S. M., Birk, D. E., et al. (2018). The Metalloproteinase-Proteoglycans ADAMTS7 and ADAMTS12 Provide an Innate, Tendon-specific Protective Mechanism against Heterotopic Ossification. JCI Insight 3 (7), e92941. doi:10.1172/jci.insight.92941

Mead, T. J., and Apte, S. S. (2018). ADAMTS Proteins in Human Disorders. Matrix Biol. 71-72, 225-239. doi:10.1016/j.matbio.2018.06.002

Murooka, T. T., Rahbar, R., Platanias, L. C., and Fish, E. N. (2008). CCL5-mediated T-Cell Chemotaxis Involves the Initiation of mRNA Translation through mTOR/4E-BP1. Blood 111 (10), 4892-4901. doi:10.1182/blood-2007-11125039 
Murphy, P. M. (2010). Double Duty for CCL21 in Dendritic Cell Trafficking. Immunity 32 (5), 590-592. doi:10.1016/j.immuni.2010.05.004

Murray, M. Y., Birkland, T. P., Howe, J. D., Rowan, A. D., Fidock, M., Parks, W. C., et al. (2013). Macrophage Migration and Invasion Is Regulated by MMP10 Expression. PLoS ONE 8 (5), e63555. doi:10.1371/ journal.pone.0063555

Mushtaq, M. U., Papadas, A., Pagenkopf, A., Flietner, E., Morrow, Z., Chaudhary, S. G., et al. (2018). Tumor Matrix Remodeling and Novel Immunotherapies: the Promise of Matrix-Derived Immune Biomarkers. J. Immunotherapy Cancer 6 (1), 65. doi:10.1186/s40425-018-0376-0

Nagase, H., Visse, R., and Murphy, G. (2006). Structure and Function of Matrix Metalloproteinases and TIMPs. Cardiovasc. Res. 69, 562. doi:10.1016/ j.cardiores.2005.12.002

Narasaraju, T., Yang, E., Samy, R. P., Ng, H. H., Poh, W. P., Liew, A.-A., et al. (2011). Excessive Neutrophils and Neutrophil Extracellular Traps Contribute to Acute Lung Injury of Influenza Pneumonitis. Am. J. Pathol. 179 (1), 199-210. doi:10.1016/j.ajpath.2011.03.013

Nishida, M., Okumura, Y., Ozawa, S.-i., Shiraishi, I., Itoi, T., and Hamaoka, K. (2007). MMP-2 Inhibition Reduces Renal Macrophage Infiltration with Increased Fibrosis in UUO. Biochem. Biophysical Res. Commun. 354 (1), 133-139. doi:10.1016/j.bbrc.2006.12.165

Parish, C. R. (2006). The Role of Heparan Sulphate in Inflammation. Nat. Rev. Immunol. 6 (9), 633-643. doi:10.1038/nri1918

Proudfoot, A. E. I., Handel, T. M., Johnson, Z., Lau, E. K., LiWang, P., Clark-Lewis, I., et al. (2003). Glycosaminoglycan Binding and Oligomerization Are Essential for the In Vivo Activity of Certain Chemokines. Proc. Natl. Acad. Sci. 100 (4), 1885-1890. doi:10.1073/pnas.0334864100

Ra, H.-J., and Parks, W. C. (2007). Control of Matrix Metalloproteinase Catalytic Activity. Matrix Biol. 26 (8), 587-596. doi:10.1016/j.matbio.2007.07.001

Raeeszadeh-Sarmazdeh, M., Do, L., and Hritz, B. (2020). Metalloproteinases and Their Inhibitors: Potential for the Development of New Therapeutics. Cells 9 (5), 1313. doi:10.3390/cells9051313

Ray, B. K., Shakya, A., Turk, J. R., Apte, S. S., and Ray, A. (2004). Induction of the MMP-14 Gene in Macrophages of the Atherosclerotic Plaque. Circ. Res. 95 (11), 1082-1090. doi:10.1161/01.res.0000150046.48115.80

Reiss, K., and Saftig, P. (2009). The "a Disintegrin and Metalloprotease" (ADAM) Family of Sheddases: Physiological and Cellular Functions. Semin. Cel Develop. Biol. 20 (2), 126-137. doi:10.1016/j.semcdb.2008.11.002

Remacle, A. G., Golubkov, V. S., Shiryaev, S. A., Dahl, R., Stebbins, J. L., Chernov, A. V., et al. (2012). Novel MT1-MMP Small-Molecule Inhibitors Based on Insights into Hemopexin Domain Function in Tumor Growth. Cancer Res. 72 (9), 2339-2349. doi:10.1158/0008-5472.can-11-4149

Roghani, M., Becherer, J. D., Moss, M. L., Atherton, R. E., Erdjument-Bromage, H., Arribas, J., et al. (1999). Metalloprotease-Disintegrin MDC9: Intracellular Maturation and Catalytic Activity. J. Biol. Chem. 274 (6), 3531-3540. doi:10.1074/jbc.274.6.3531

Rot, A. (1992). Binding of Neutrophil Attractant/activation Protein-1 (Interleukin 8) to Resident Dermal Cells. Cytokine 4 (5), 347-352. doi:10.1016/10434666(92)90077-5

Rot, A. (2010). Chemokine Patterning by Glycosaminoglycans and Interceptors. Front. Biosci. 15, 645-660. doi:10.2741/3638

Ruffell, B., and Johnson, P. (2008). Hyaluronan Induces Cell Death in Activated $\mathrm{T}$ Cells through CD44. J. Immunol. 181 (10), 7044-7054. doi:10.4049/ jimmunol.181.10.7044

Salter, R. C., Arnaoutakis, K., Michael, D. R., Singh, N. N., Ashlin, T. G., Buckley, M. L., et al. (2011). The Expression of a Disintegrin and Metalloproteinase with Thrombospondin Motifs 4 in Human Macrophages Is Inhibited by the Antiatherogenic Cytokine Transforming Growth Factor- $\beta$ and Requires Smads, P38 Mitogen-Activated Protein Kinase and C-Jun. Int. J. Biochem. Cel Biol. 43 (5), 805-811. doi:10.1016/j.biocel.2011.02.005

Santamaria, S. (2020). ADAMTS-5: A Difficult Teenager Turning 20. Int. J. Exp. Pathol. 101 (1-2), 4-20. doi:10.1111/iep.12344

Santamaria, S., Cuffaro, D., Nuti, E., Ciccone, L., Tuccinardi, T., Liva, F., et al. (2021). Exosite Inhibition of ADAMTS-5 by a Glycoconjugated Arylsulfonamide. Sci. Rep. 11 (1), 949. doi:10.1038/s41598-020-80294-1

Santamaria, S., and de Groot, R. (2019). Monoclonal Antibodies against Metzincin Targets. Br. J. Pharmacol. 176 (1), 52-66. doi:10.1111/bph.14186
Santamaria, S., Yamamoto, K., Botkjaer, K., Tape, C., Dyson, M. R., McCafferty, J., et al. (2015). Antibody-based Exosite Inhibitors of ADAMTS-5 (Aggrecanase2). Biochem. J. 471 (3), 391-401. doi:10.1042/bj20150758

Shiraishi, A., Mochizuki, S., Miyakoshi, A., Kojoh, K., and Okada, Y. (2016). Development of Human Neutralizing Antibody to ADAMTS4 (Aggrecanase-1) and ADAMTS5 (Aggrecanase-2). Biochem. Biophysical Res. Commun. 469 (1), 62-69. doi:10.1016/j.bbrc.2015.11.072

Siddhartha, R., and Garg, M. (2021). Molecular and Clinical Insights of Matrix Metalloproteinases into Cancer Spread and Potential Therapeutic Interventions. Toxicol. Appl. Pharmacol. 426, 115593. doi:10.1016/ j.taap.2021.115593

Spillmann, D., Witt, D., and Lindahl, U. (1998). Defining the Interleukin-8Binding Domain of Heparan Sulfate. J. Biol. Chem. 273 (25), 15487-15493. doi:10.1074/jbc.273.25.15487

Suwan, K., Choocheep, K., Hatano, S., Kongtawelert, P., Kimata, K., and Watanabe, H. (2009). Versican/PG-M Assembles Hyaluronan into Extracellular Matrix and Inhibits CD44-Mediated Signaling toward Premature Senescence in Embryonic Fibroblasts. J. Biol. Chem. 284 (13), 8596-8604. doi:10.1074/ jbc.m806927200

Swee, M., Wilson, C. L., Wang, Y., McGuire, J. K., and Parks, W. C. (2008). Matrix Metalloproteinase-7 (Matrilysin) Controls Neutrophil Egress by Generating Chemokine Gradients. J. Leukoc. Biol. 83 (6), 1404-1412. doi:10.1189/ jlb.0108016

Syed, F., Li, W., Relich, R. F., Russell, P. M., Zhang, S., Zimmerman, M. K., et al. (2021). Excessive Matrix Metalloproteinase-1 and Hyperactivation of Endothelial Cells Occurred in COVID-19 Patients and Were Associated with the Severity of COVID-19. J. Infect. Dis. 224, 60. doi:10.1093/infdis/ jiab167

Tang, B. L. (2001). ADAMTS: a Novel Family of Extracellular Matrix Proteases. Int. J. Biochem. Cel Biol. 33 (1), 33-44. doi:10.1016/s13572725(00)00061-3

Tsuji, N., Matsuura, T., Narama, I., Yoshiki, A., and Ozaki, K. (2018). MacrophageAssociated Gelatinase Degrades Basement Membrane at the Optic Fissure Margins during Normal Ocular Development in Mice. Invest. Ophthalmol. Vis. Sci. 59 (3), 1368-1373. doi:10.1167/iovs.17-21841

Varga, Z. s., Jacob, M. P., Robert, L., Csongor, J., and Fulop, T., Jr (1997). Agedependent Changes of K-Elastin Stimulated Effector Functions of Human Phagocytic Cells: Relevance for Atherogenesis. Exp. Gerontol. 32 (6), 653-662. doi:10.1016/s0531-5565(97)00042-9

Vermaelen, K. Y., Cataldo, D., Tournoy, K., Maes, T., Dhulst, A., Louis, R., et al. (2003). Matrix Metalloproteinase-9-Mediated Dendritic Cell Recruitment into the Airways Is a Critical Step in a Mouse Model of Asthma. J. Immunol. 171 (2), 1016-1022. doi:10.4049/jimmunol.171.2.1016

Wågsäter, D., Björk, H., Zhu, C., Björkegren, J., Valen, G., Hamsten, A., et al. (2008). ADAMTS-4 and -8 Are Inflammatory Regulated Enzymes Expressed in Macrophage-Rich Areas of Human Atherosclerotic $\begin{array}{lllll}\text { Plaques. Atherosclerosis } 196 & \text { (2), 514-522. doi:10.1016/ }\end{array}$ j.atherosclerosis.2007.05.018

Wang, S., Quang Le, T., Chida, J., Cisse, Y., Yano, M., and Kido, H. (2010). Mechanisms of Matrix Metalloproteinase-9 Upregulation and Tissue Destruction in Various Organs in Influenza A Virus Infection. J. Med. Invest. 57 (1-2), 26-34. doi:10.2152/jmi.57.26

Wang, W.-M., Ge, G., Lim, N. H., Nagase, H., and Greenspan, D. S. (2006). TIMP-3 Inhibits the Procollagen N-Proteinase ADAMTS-2. Biochem. J. 398 (3), 515-519. doi:10.1042/bj20060630

Watanabe, R., Maeda, T., Zhang, H., Berry, G. J., Zeisbrich, M., Brockett, R., et al. (2018). MMP (Matrix Metalloprotease)-9-Producing Monocytes Enable T Cells to Invade the Vessel Wall and Cause Vasculitis. Circ. Res. 123 (6), 700-715. doi:10.1161/circresaha.118.313206

Wight, T. N. (2002). Versican: a Versatile Extracellular Matrix Proteoglycan in Cell Biology. Curr. Opin. Cel Biol. 14 (5), 617-623. doi:10.1016/s0955-0674(02) 00375-7

Wondimu, Z., Geberhiwot, T., Ingerpuu, S., Juronen, E., Xie, X., Lindbom, L., et al. (2004). An Endothelial Laminin Isoform, Laminin 8 ( $\alpha 4 \beta 1 \gamma 1)$, Is Secreted by Blood Neutrophils, Promotes Neutrophil Migration and Extravasation, and Protects Neutrophils from Apoptosis. Blood 104 (6), 1859-1866. doi:10.1182/ blood-2004-01-0396 
Wu, B., Crampton, S. P., and Hughes, C. C. W. (2007). Wnt Signaling Induces Matrix Metalloproteinase Expression and Regulates T Cell Transmigration. Immunity 26 (2), 227-239. doi:10.1016/j.immuni.2006.12.007

Wu, C., Ivars, F., Anderson, P., Hallmann, R., Vestweber, D., Nilsson, P., et al. (2009). Endothelial Basement Membrane Laminin a5 Selectively Inhibits T Lymphocyte Extravasation into the Brain. Nat. Med. 15 (5), 519-527. doi:10.1038/nm.1957

Yen, J.-H., Khayrullina, T., and Ganea, D. (2008). PGE2-induced Metalloproteinase-9 Is Essential for Dendritic Cell Migration. Blood 111, 260. doi:10.1182/blood-2007-05-090613

Conflict of Interest: The authors declare that the research was conducted in the absence of any commercial or financial relationships that could be construed as a potential conflict of interest.
Publisher's Note: All claims expressed in this article are solely those of the authors and do not necessarily represent those of their affiliated organizations, or those of the publisher, the editors and the reviewers. Any product that may be evaluated in this article, or claim that may be made by its manufacturer, is not guaranteed or endorsed by the publisher.

Copyright (®) 2021 McMahon, Ye, Pedrina, Dlugolenski and Stambas. This is an open-access article distributed under the terms of the Creative Commons Attribution License (CC BY). The use, distribution or reproduction in other forums is permitted, provided the original author(s) and the copyright owner(s) are credited and that the original publication in this journal is cited, in accordance with accepted academic practice. No use, distribution or reproduction is permitted which does not comply with these terms. 